\title{
PRODUCCIÓN DE PAPA EN ZONAS ÁRIDAS Y SALINAS A PARTIR DE SEMILLA BOTÁNICA FACTIBILIDAD Y PERSPECTIVAS
}

René Chávez Alfaro', Mahesh Upadhya ${ }^{2}$, Rolando Cabello ${ }^{3}$, Rafael Berrios ${ }^{4}$, Porfirio Siles ${ }^{4}$.

\section{R E S U M E N}

La papa es el cultivo mas importante en el Peru, donde más de 200000 hectáreas son cultivadas bajo las diversas condiciones agroecológicas existentes. Los obstáculos técnicos más importantes para mejorar la producción de papa en el Perú son la escasez de semilla de buena calidad, y la susceptabilidad de las variedades existentes a plagas y enfermedades importantes.

Las principales ventajas de usar semilla botánica en vez de tubérculossemillas son : la semilla botánica disminuye al mínimo los problemas asociados con plagas y enfermedades transmitidas por el tubérculo y sólo muy pocos patógenos pueden ser portados por la semilla. Asi mismo la semilla botánica puede ser almacenada por los agricultores en forma conveniente y barata de una temporada de siembra a otra o durante varios años, también su transporte es fácil y económico. La semilla botánica puede ser incorporada fácilmente en los sistemas agrícolas existentes porque el tiempo de siembra no depende de la fase de brotamiento de los tubérculos-semilla, pudiendo extenderse la papa a regiones donde antes no podía ser cultivada, como son las áreas tropicales, cálidas y húmedas porque allí es difícil producir y almacenar tubérculossemillas de buena calidad. Otra de las principales ventajas de la semilla botánica es que es un material de bajo costo que puede reducir el costo total de producción. Para sembrar una hectárea, los agricultores necesitan solamente alrededor de 100 gramos de semilla botánica, comparados con dos toneladas de tubérculos semillas.

\section{ANTECEDENTES DEL PROYECTO DE MEJORAMIENTO GENÉTICO DE LA PAPA PARA ZONAS ÁRIDAS Y SALINAS DEL PERÚ}

El descubrimiento de la variabilidad genética para resistencia y salinidad y sequia en el germoplasma hexaploide nativo y cultivares del camote $(2 n=6 x=90=B B B B B B)$ y en poblaciones

1. PhD. Mejoramiento genético de plantas (UNJBG).

2. PhD. Fisiologia y genética vegetal (CIP).

3. Msc. Fisiología vegetal (CIP).

4. Bch. en Agronomía (UN.JBG). clonales tetraploides de papa $(2 n=4 x=48=A A A A)$ a principios de 1985, catalizó el inicio de una investigación aplicada sobre respuestas fenotípicas de las plantas tuberíferas a los estreses abióticos más comunes de las zonas áridas y salinas de la costa peruana. De esta manera se estableció el mismo año en zonas costaneras representativas el proyecto de investigación colaborativa de Mejoramiento genético de papa y camote para zonas árido-salinas entre la facultad de Ciencias Agrícolas de la Universidad Nacional de Tacna y el Centro Internacional de la Papa (CHAVEZ et al, 1992). 
Dentro de la estrategia de selección recurrente y logistica del proyecto se diseñó un programa de cruzamientos y selecciones para generar clones y familias híbridas superiores, asi como progenitores de buena habilidad combinatoria adaptados a las condiciones de aridez y salinidad de los suelos marginales de la costa peruana. Este germoplasma mejorado, una vez multiplicado, limpiado de virus, y liberado sería utilizado por los agricultores de esta zona agroecológica para la alimentación humana, como forraje y materia prima para la agroindustria. Desde aquella fecha, hasta hoy dia, se ha generado una amplia ganancia genética y un extenso avance de selección materializado fundamentalmente por un caudal de clones, hibridos y variedades superiores adaptadas a las condiciones climáticas y edáficas de la costa sur peruana, asi como una amplia resistencia de campo al nemátodo del nudo de la raiz, Meloidogyne javanica, $M$. incognita y $M$. arenaria (CHAVEZ, et al 1993, 1995).

\section{EL DESIERTO Y EL ESTRÉS ABIÓTICO}

En los suelos salinos con potencial agrícola del sur del Peru la sal predominante es el cloruro de sodio. La salinidad del suelo se mide con los conductímetros que valoran el nivel de sal en el suelo en $\mathrm{mmh} / \mathrm{cm} /$ $25^{\circ} \mathrm{C}$. La conductividad eléctrica de los suelos salinos fluctua entre 5 y $25 \mathrm{mmh} / \mathrm{cm}$. Poniendo un ejemplo diremos que un suelo de una CE de $5 \mathrm{mmh} / \mathrm{cm}$ tiene aproximadamente $1 \%$ de cloruro de sodio en el suelo. Lo cual es una cantidad suficiente para causar serio estrés a muchas plantas cultivadas.

El problema de la salinización de las tierras agricolas en el sur del Perú puede ser resuelto primariamente mediante la manipulación del medio ambiente a través de proyectos de drenaje y lavado de los suelos. Sin embargo, estos procedimientos envuelven una gran cantidad de agua, además es un procedimiento costoso y de efectos positivos poco estables. Pensamos que la solución más fácil y sostenible es mejorar genéticamente las plantas para su adaptación a las condiciones agricolas desérticas (CHAVEZ, 1995).

En general, los suelos áridos-salinos tienen concentraciones elevadas de boro cuyo rango fluctua de 4 a $10 \mathrm{ppm}$. Las plantas en su mayoria requieren boro para su metabolismo en concentraciones de 0.5 a $3 \mathrm{ppm}$. Una deficiencia de boro a niveles menores de 1 a $0.5 \mathrm{ppm}$ en el suelo produce un estrés en la planta. En plantas como el tomate, zapallo, sandia y aun en la papa produce ennegrecimiento, pudrición y caida temprana de frutos inmaduros. Por el contrario, una concentración elevada de boro de 4 a 10 ppm produce una toxicidad en la planta, como sucede en los citricos, la yuca, palta, guayaba, papa y camote entre otros, mostrando fuertes quemaduras en los bordes de las hojas, reducción marcada en el rendimiento y clorosis (CHAVEZ et al 1992).

Las comparaciones de los diferentes niveles de salinidad del suelo han demostrado que la reducción del rendimiento es mayor a intervalos largos de riego que a intervalos cortos. Incrementándose la concentración de sales en la zona radicular con las temperaturas elevadas del verano (tab. 1,2,3,4).

Los niveles de salinidad en el suelo a $4 \mathrm{mmh} /$ $\mathrm{cm}$ no tiene efectos significativos en el rendimiento del camote y la papa, pero a niveles superiores de 5 $\mathrm{mmh} / \mathrm{cm}$, especialmente entre 8 a $12 \mathrm{mmhs}$, hay una drástica reducción en el crecimiento de la planta, sea donde y cuando es aplicada la sal. En este sentido la papa y el camote son susceptibles a la salinidad y otros estreses del desierto. Los rendimientos son drásticamente reducidos a medida que se incremente el contenido de sal y boro en el suelo. Sin embargo, los genotipos de papa y camote evaluados en suelos árido-salinos han mostrado diferentes respuestas de rendimiento bajo un mismo estrés de salinidad, toxicidad de boro y sequia. Además, la diferencia de los resultados de experimentos de verano e invierno muestran el efecto del clima en la acción de las sales, debido a la evaporación y capacidad de campo del suelo (CHAVEZ, et al 1993).

\section{BASES CIENTIFICAS DE LA SEMILLA BOTÁNICA}

\subsection{ORIGEN Y OBJETIVOS}

Las primeras variedades de papa con valor comercial son originarias de las partes altas de los Andes, de donde fueron llevadas por los conquistadores españoles a Europa, distribuyéndose luego por todo el Mundo, para constituirse en el alimento más importante de la humanidad como fuente de energia, ya que produce de dos a cuatro veces más que el maiz y de seis a diez veces que los cereales pequeños o de cosecha fina.

Desde hace varias décadas, los genetistas dedicados al mejoramiento de las variedades de papa y la obtención de hibridos han logrado notables avances. En los últimos años, los principales trabajos cientificos sobre este cultivo, se han puesto bajo la dirección de CENTRO INTERNACIONAL DE LA PAPA, con sede en la 
Estación Experimental "La Molina" situada en Lima Perú. Este Centro es financiado por el Grupo Consultivo de Investigación Agrícola Internacional y sus metas son aumentar la producción de la papa en los paises del tercer mundo y buscar nuevas áreas aptas para el tubérculo en zonas altas y también en las bajas con clima tropical. Los principales objetivos de ésta investigación científica son:

a) La alta productividad,

b) El mejoramiento de las cualidades comerciales, adaptadas desde luego a las exigencias del mercado en cada pais,

c) La resistencia a numerosas y diversas enfermedades, plagas y virus que atacan a los cultivos de papa.

En cuanto a producción por unidad de superficie y calidad los logros han sido extraordinarios. También se ha conseguido cultivares con poca o mucha resistencia a enfermedades, insectos, nemátodos y virus; aunque en este campo los problemas continúan por varias razones. El proceso técnico para lograr nuevas variedades o híbridos requiere muchos años de complicados trabajos y no es fácil reunir todas las características deseables en una sola variedad, debido a problemas genéticos. Sin embargo, cuando se logran cultivares resistentes a enfermedades o plagas, se presenta otro serio inconveniente.

\subsection{AVANCE DE SELECCIÓN}

Para generar familias de semilla botánica de papa, se utilizan diferentes métodos de mejoramiento, los cuales poseen las caracteristicas necesarias para la producción de tubérculos por planta y una uniformidad de caracteres agronómicos aceptables en color, forma y madurez. Un gran número de buenos progenitores han sido identificados, basados en los estudios de habilidad combinatoria general y específica de muchos clones y cultivares de las poblaciones del trópico bajo, tales como los clones superiores LT. Estas lineas parentales fueron posteriormente intercruzadas para obtener diferentes grupos de familias, pero estos grupos de familias híbridas (semilla botánica) han sido evaluados en diseños para el rendimiento de otros caracteres en diferentes estaciones experimentales del Perú y de otros paises tropicales, incluyendo la Rep. Popular China. Los resultados muestran que existen un gran número de familias hibridas que dan un rendimiento muy aceptable para el mercado en un promedio de $1.2 \mathrm{Kg}$ de papa por planta con una uniformidad que fluctúa entre aceptable y excelente. (CIP 1990), (MALAGAMBA 1984).

El rendimiento y uniformidad de algunas familias de semilla botánica fueron tan buenas como el rendimiento de las variedades comerciales producidas a partir de tubérculo-semilla. Algunas de estas familias han sido aprobadas en la Universidad Nacional de Tacna, habiendo mostrado casi todas ellas susceptibilidad a suelos áridos y salinos; en este aspecto, en la UNJBG se está tratando de encontrar híbridos de semilla botánica que se adapten a las condiciones desérticas de Tacna y Moquegua. (CHAVEZ et al, 1992).

Estas diminutas semillas de papa, plantando en pequeños huertos y parcelas de terreno producen papas de buena calidad, tanto como para consumo inmediato como para semilla-tubérculo. Las semillas provienen de genotipos clonales mejorados a través de un largo proceso de combinaciones convencionales y de manipulación cromosómica.

Tal vez la ventaja más notable de la semilla botánica frente a la semilla-tubérculo es la cantidad necesitada para plantar en una hectárea. Se necesita sólo aproximadamente $100 \mathrm{gr}$. de semilla botánica para una hectárea, mientras que de semilla tubérculo se necesitan $2 \mathrm{TM}$, para una hectárea. Una $\mathrm{Ha}$. de papa destinada a la producción de semilla da 24 TM/ Ha y sirve para sembrar otras 12 Hás, mientras que de $1 \mathrm{Ha}$ de papa destinada a la producción de semilla botánica sirve para sembrar otras $1400 \mathrm{Has}$ (CHAVEZ 1990, MALAGAMBA 1984, GOLMIRZAIE et al 1990).

Los problemas asociados con la transmisión de enfermedades a través de los tubérculos son minimizadas con la semilla botánica, debido a que esta no transmite la mayoria de las enfermedades virósicas, fungosas y bacterianas transmitidas a través de los tubérculos, (CIP 1990).

Es necesario enfatizar que la semilla botánica de bajo costo no competirá con la semilla tubérculo ya establecida y costosa especializada en zonas temperadas y muchas regiones templadas y frías del cinturón tropical, pero si se presenta como una alternativa ventajosa donde técnicamente hay limitaciones en el manejo de semilla tubérculo, donde hay buena disponibilidad de mano de obra, donde hay mucha escasez de alimentos y en lugares donde se ha podido cultivar papa, como en las selvas húmedas y calurosas. (CHAVEZ 1990, CIP 1991).

Otras ventajas del uso de semilla botánica de papa son su fácil almacenamiento y transporte, se 
evitarán enfermedades virósicas, fungosas y bacterianas, constituyéndose una semilla certificada de bajo costo (su dormancia se rompe utilizando ácido giberélico a 2000 ppm). (CHAVEZ 1990).

El tamaño del tubérculo es un factor importante para un "rendimiento comercial" de aceptación en el mercado, más que el rendimiento total de tubérculos del cultivo. En algunos mercados son aceptados grandes tubérculos (papa frita y al horno), en otros mercados prefieren tubérculos pequeños (semilla). EI rendimiento comercial es fuertemente influenciado por dos factores: el total rendimiento, y el número de tubérculos por unidad de área. El número de tubérculos es altamente dependiente de la densidad vegetal o distanciamiento. (CHAVEZ 1990, MALAGAMBA 1984, GOLMIRZAIE et al 1990).

La tarea de mejoramiento programado incluye la producción de TPS en policruzas y luego una selección masal en la búsqueda de variedades tolerantes a salinidad y sequia, de mayor precosidad, mejor calidad industrial y culinaria, asi como el mayor rendimiento por hectárea. (CHAVEZ 1990).

Realmente pocos ejemplos pueden ser mencionados de una tecnología que tuvo que atraer y rebuscar mucho e interesar, como una semilla de papa efectiva (TPS : true potato seed: Semilla verdadera de papa) que se estuvo desarrollando en algunos paises en los recientes años. Este gran interés originado por la gran flexibilidad ofrecida por TPS en pedir diferentes condiciones agroeconómicas y por el rápido progreso hecho, desarrollando materiales y técnicas que pueden tener aplicación en muchas regiones del mundo. Verdaderamente la gran proporción de las áreas con gran potencial para adopción o uso de TPS puede beneficiar por su fácil manejo y materiales uniformes desarrollados en el CIP y en otras instituciones, (MALAGAMBA 1984, CIP 1992).

Para nuestro conocimiento el uso de TPS en el presente viene siendo investigado en más de 40 paises de los más desarrollados. En varios de aquellos países los métodos de utilización son evaluados como alternativas en estaciones experimentales y bajo condiciones de campo del agricultor, (MALAGAMBA 1984, GOLMIRZAIE et al 1990).

\subsection{CONDICIONES AGROECONÓMICAS Y ECOLÓGICAS}

Diferentes medidas y resultados de trabajos en chacra de agricultores en varios regiones del Perú indican ese potencial para adopción de TPS. La tecnología puede ir especialmente a favorecer aunque, siguiendo con las condiciones agroeconómicas generales presentes:

a) El clima debe ser apropiado para producir papa por un período mayor de tres meses.

b) La producción de papa es baja debido a la baja calidad de la semilla tubérculo.

c) El costo de la semilla tubérculo representa una alta proporción del total del costo de producción.

d) Las prácticas de crecimiento en hortalizas son abundantes y baratas.

e) El precio de papa en el mercado es relativamente alto.

f) El mercado tiene normas aunque aún no son estrictas sobre la uniformidad del tubérculo.

g) El área dedicada para el cultivo de la papa en las chacras es grande, (MALAGAMBA 1984 , WIERSEMA 1988).

En general estas condiciones pueden ser establecidas en dos tipos de zonas o áreas:

1) Aquellos que actualmente están cultivadas con papa para semilla tubérculo, pero donde TPS puede ser un viable sustituto para producir semilla limpia con muchos beneficios.

Estas zonas pueden ser caracterizadas por grandes mercados que tienen normas establecidas $y$, antes de esto. TPS no solamente pueda tener y ofrecer ventajas económicas, sino también pueda encontrar una calidad de nivel competitivo. En zonas sustituidas por alta producción y calidad en cuanto a uniformidad del tubérculo son casos de particular importancia, (MENDOZA 1983).

2) Aquellas de potencial de expansión de la cosecha, zonas donde actualmente la papa no es cultivada o tiene una importancia secundaria en el amplio sistema de cultivos. Zonas donde el crecimiento vegetativo y los trabajos son especializados y abundantes en grandes chacras en el cálido trópico. Ahora son buenas evidencias que en estas áreas aparece TPS para obtener la mayor e inmediata adopción del potencial, (MALAGAMBA 1984, ATLIN 1984).

El fin de utilizar la TPS es tener papa para producción; pueden ser distinguidos dos sistemas básicos: siembra directa de TPS y realizando 
trasplante de plantas al campo definitivo, (MALAGAMBA 1984, GOLMIRZAIE et al 1990).

La papa puede reproducirse sexualmente plantando las pequeñas semillas que se forman en frutos chicos similares al tomate. Sin embargo, con pocas excepciones, la mayoría de los productores de papa en el mundo plantan tubérculos. Este tipo de reproducción vegetativa es una de las caracteristicas distintivas del cultivo de la papa. Este hecho no sólo determina fuertemente como se cultiva la papa, sino que también determina dónde, quien, y para qué usos la cultivan. En la mayoría del Tercer mundo, la escasez y el costo elevado de los tubérculos-semillas de buena calidad constituye una restricción seria a la producción de papa, (HORTON 1992, ACCATINO 1992).

La investigación en semilla sexual de papa comenzó en 1977 para desarrollar una alternativa a la propagación vegetativa de la papa. La semilla sexual de papa tiene aplicaciones potenciales en programas nacionales de semillas y en las fincas. Su uso podría abaratar el material de plantación e incrementar significativamente la cantidad de tubérculos en mercado de papa-consumo, (HORTON 1992, MALAGAMBA 1982).

Actualmente, se estima en 10 millones de toneladas la cantidad de papa que se destina anualmente a la siembra en los países del Tercer Mundo. La semilla sexual de papa es mucho mas fácil de almacenar que los tubérculos-semillas y su uso podría disminuir sensiblemente la diseminación de enfermedades causadas por virus y transmitidas por tubérculos, (HORTON 1992, WIERSEMA 1988).

Las prioridades asignadas a la investigación en semilla sexual de papa incluyen el desarrollo de poblaciones uniformes, tempranas, y de alto rendimiento; la mejora en los métodos de producción de semillas; y la determinación de la posibilidad técnica y económica de diferentes sistemas de multiplicación usando semillas de papa en paises en desarrollo, (HORTON 1992, MENDOZA 1979).

En el método de siembra directa en el campo de TPS, las características de la semilla y el normal desarrollo lento del vigor de la planta limitan el uso

\section{HeMfroteca CENTRAL UNIBG}

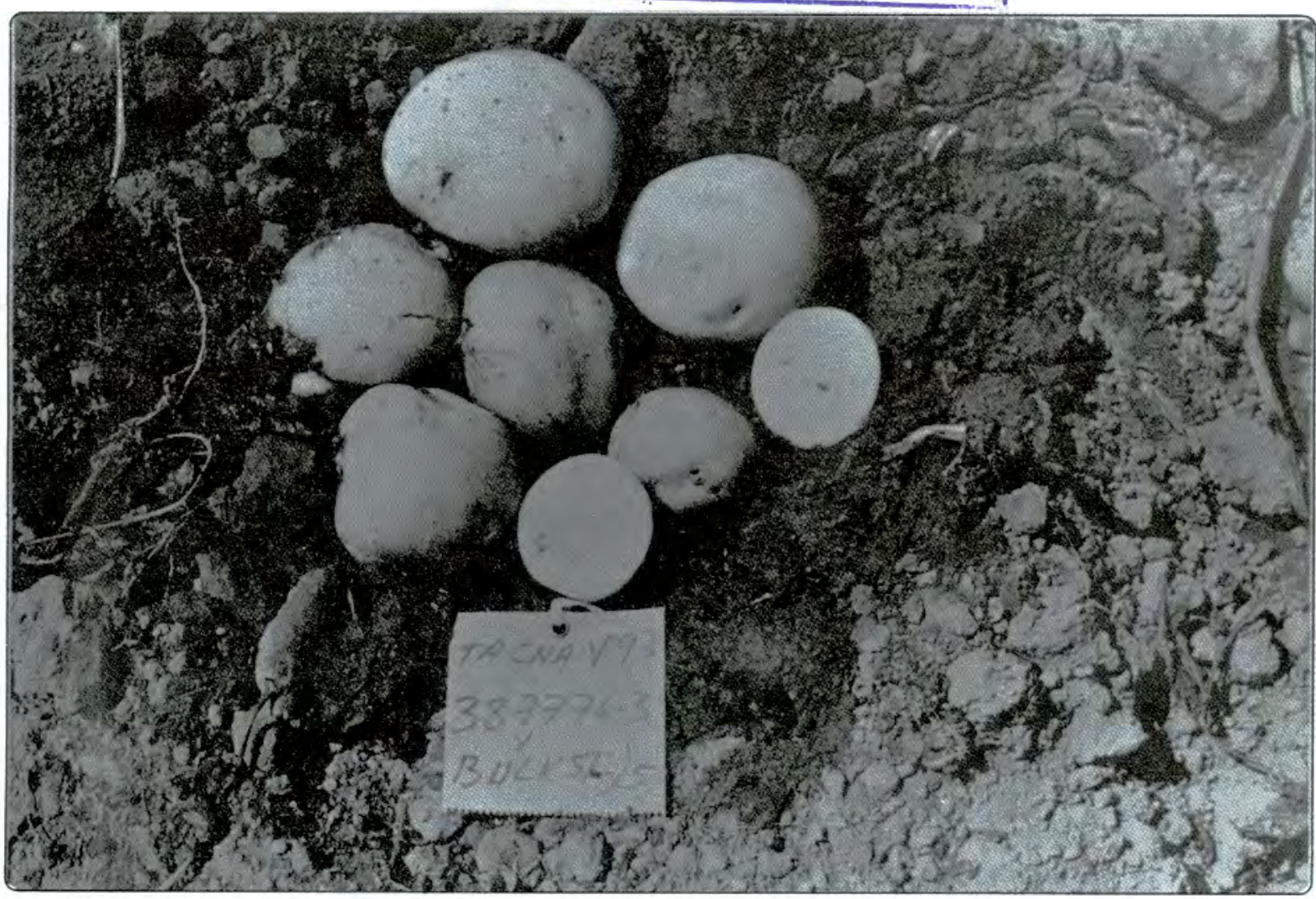

El clon élite progenitor de semilas botánicas SDC.387776.3 ha mostrado una progenie promisoria bajo condiciones árido-salinas. 
de este método en grandes zonas que pueden ser manejadas intensivamente. Por eso, este método tuvo excelente aplicación en la producción de plantas tubérculo en camas de producción donde puede ser obtenida una alta producción y en áreas más grandes solamente con prácticas apropiadas de manejo. Porque de la alta cantidad de plantas-tubérculo obtenidas por multiplicación se obtiene una gran producción; al inicio, en las camas de producción por extensión se puede producir suficientes tubérculos para plantar un campo grande en la siguiente estación, (MALAGAMBA 1982), CIP 1990).

El sistema de trasplante de plántulas al campo definitivo tuvo que mostrar, entre otras ventajas, la posibilidad de producir plantas vigorosas en almácigos, y trasplantando en cualquier tiempo si las condiciones son apropiadas. Esto permite un eficiente uso de la tierra y vencer la limitante de la siembra directa de TPS. Cuando las condiciones son favorables para el trasplante de plántulas puede ser utilizado también como material para la siguiente estación. Como sea, en zonas de expansión del potencial de la cosecha, particularmente en aquellas regiones del trópico, la producción directa de papa para trasplante aparece como el sistema más adecuado. Bajo estas condiciones, la posibilidad de utilizar la planta-tubérculo para plantar o sembrar en la siguiente estación es limitado por la poca aptitud de estas zonas al almacenamiento y conservación de la calidad de la semilla-tubérculo en cuanto a calidad; también se le expone a virus y enfermedades, (MALAGAMBA 1984, CIP 1992).

El propósito de la investigación en TPS es demostrar la factibilidad de la producción y determinar el potencial de rendimiento comercial de la papa a partir de semilla botánica mejorada, en zonas áridas utilizando híbridos superiores. Es problemática de los Valles de Tacna y Moquegua la escasez del recurso hidrico y su elevado costo de extracción dependiendo de la zona de cultivo, se presentan también diferentes minerales y no minerales a niveles cercanamente tóxicos que trae en suspensión el agua ya sea de origen subterráneo o de origen fluvial; los cuales pueden actuar en detrimento del cultivo de la papa, el camote y de otros cultivos (CHAVEZ et al 1992).

\subsection{VENTAJAS Y DESVENTAJAS DE LA SEMILLA BOTÁNICA VS SEMILLA TUBÉRCULO}

Comparación de producción de papa usando semilla botánica y tubérculos semilla.
SEMILLA BOTANICA (TPS)

1) $80 \mathrm{a} 120 \mathrm{~g} / \mathrm{Ha}$ de semilla según la densidad de siembra o de trasplante

2) Libre de nematodos, insectos, bacterias, hongos y la mayoria de virus.

3) Requiere mayor labor en la fase inicial del cultivo.

4) En las etapas iniciales de crecimiento de la planta, esta es más vulnerable a la competencia de malezas, plagas, enfermedades y estreses. En esta etapa se requiere irrigación artificial.

5) Tendencia a madurar $15-20$ dias más tarde. Rendimiento comparable o mayor. Gran número de tubérculos pequeños. Menor uniformidad en factores de calidad de tuberculos.

6) Los tubérculos son menos adecuados para procesamiento industrial.

7) Costo de almacenamiento y transporte extremadamente bajo.

8) El costo total de producción se reduce por eliminación de los costos en tubérculos semilla, almacenamiento y transporte.

9) Es fácil de almacenar por mucho tiempo. Su distribución es fàcil y económica. Se adapta fácilmente a los sistemas de cultivo debido a que la época de siembra no depende del envejecimiento de los tubérculos.

GOLMIRZAIE, ORTIZ y SERQUEN (1990). MALAGAMBA (1984).

\section{ESTRATEGIAS DE MEJORAMIENTO PARA LA PRODUCCIÓN DE SEMILLA BOTÁNICA DE PAPA}

El uso de la semilla sexual o botánica de papa puede superar los problemas de almacenamiento, transporte y enfermedades asociadas con el uso de tubérculo-semilla en muchos paises del Tercer Mundo, y permitirá la expansión de la producción de este cultivo a las zonas de climas tropicales y subtropicales, en varias regiones del mundo. Factores ecológicos tales como poblaciones elevadas de áfidos (en el Perú se han identificado cerca de 10 especies de áfidos), y la presencia de enfermedades durante todo el año. dificultan el mantenimiento de sus propios programas de tubérculos-semillas de categoria certificada. Como resultado, muchos paises importan tubérculos- 
semillas de paises de clima templado y, por consiguiente, los costos de producción de papa para consumo con muy altos.

Estas limitaciones para la producción de tubérculos-semilla de alta calidad y para la expansión de la papa hacia nuevas áreas donde tiene potencia como un cultivo alimenticio valioso, hacen del uso de la semilla sexual una alternativa atractiva respecto al uso de tubérculo-semilla para el incremento de la producción de papa.

En las regiones andinas, la semilla sexual ha sido utilizada desde la antigüedad, probablemente desde el inicio de su cultivo, para la producción de papa. Los Incas utilizaron prácticas culturales avanzadas y conocieron como trasplantar, pudiendo haber aprendido el uso de esta semilla como una curiosidad (MALAGAMBA Y MONARES, 1988). Algunos informes demuestran que la semilla sexual parece haber sido utilizada exclusivamente como método para producir nuevas variedades, un ejemplo del cual fue reportado en Inglaterra hacia fines del siglo XVIII (GEDDES, 1988).

Al finalizar la década de 1880 , los comerciantes de semillas anunciaban la semilla sexual de papa en sus catálogos en los Estados Unidos, y en el Reino Unido se mantuvo esta práctica por lo menos hasta 1939 (GEDDES, 1989). En China, un pais que ha ganado reconocimiento por su trabajo pionero en semilla sexual de papa, la historia de esta semilla se remonta a 1959 cuando se inició la investigación. En dicho pais, la producción en gran escala de este tipo de semilla se inició a comienzos de la década de 1960 (SON BO-FU et al, 1987).

En 1976 el Centro Internacional de la Papa (CIP) empezó investigaciones sobre el uso de propagación sexual del cultivo de la papa como una alternativa a la propagación asexual para incrementar su producción en paises del tercer mundo. Desde entonces se ha llevado a cabo un gran número de investigaciones en las áreas de mejoramiento, agronomia y fisiologia, a fin de optimizar la producción y simplificar la tecnología de la semilla sexual para su mejor aportación por parte de los agricultores.

La propagación de la papa vía semilla sexual genera preguntas importantes que sólo ha recibido una atención mínima en el mejoramiento y producción tradicionales del cultivo. Esto se debe a las diferencias entre un clon y una progenie de semilla sexual de papa. Un clon es una colección grande de individuos genotípicamente idénticos que mantienen su identidad genotípica a menos que ocurra una mutación somática. Cada uno de estos individuos se deriva de una sola planta heterozigota. Una progenie de semilla sexual es una colección grande de individuos, fenotipicamente diferentes inos de otros, pero con suficiente uniformidad genotipica en las caracteristicas de los tubérculos, originados por propagación sexual (CIP, Informe Anual 1987). Esta diferencia básica entre un clon y una progenie con buen rendimiento y uniformidad para un cierto número de características que se sometieron a consideración al inicio de la investigación del CIP sobre producción por semilla asexual fueron germinación, uniformidad, forma y vigor de la planta durante el periodo de crecimiento asi como también forma, color, tamaño y número de tubérculos al momento de la cosecha.

La producción de la semilla es una barrera para la expansión de la tecnologia de la semilla sexual en los paises del tercer mundo. Los caracteres reproductivos tales como la intensidad de floración y la producción de bayas en la papa son favorecidos por días largos (15 a 17 horas) y temperatura medias $\left(15\right.$ a $\left.18^{\circ} \mathrm{C}\right)$. Por consiguiente, bajo las condiciones cálidas encontradas en latitudes tropicales (12-13 horas de longitud del dia y $20-28^{\circ} \mathrm{C}$ ), la producción de semilla sexual es mas difícil. La floración escasa y la reducida fertilidad del polen, causantes de la baja producción de bayas y semillas, son las principales limitaciones para producir la semilla sexual en los ambientes cálidos (MALAGAMBA, 1988). No obstante las zonas tropicales calurosas, donde el tubérculosemilla es costoso y su calidad se deteriora rápidamente debido a la alta temperatura e incidencia de enfermedades transmitidas por tubérculos, parece tener el mayor potencial para el uso de la tecnologia de semilla sexual.

En consecuencia, la selección de lineas parentales de semilla sexual con respecto a caracteres productivos, en combinación con caracteres agronómicos, ha sido llevada a cabo bajo las condiciones tropicales de la estación experimental del CIP en San Ramón, que presenta 12.5 horas de longitud de dia a una temperatura promedio de $24^{\circ} \mathrm{C}$.

En paises en desarrollo, la producción de papa a base de semilla botánica se está convirtiendo en una alternativa promisoria frente al método tradicional de usar tubérculos-semillas. Por varias razones, la papa ha sido tradicionalmente propagada sembrando tubérculos-semillas: estos son fáciles de sembrar y las plantas crecen rápida y vigorosamente. Los tubérculos cosechados son uniformes y los 
rendimientos son generalmente altos. A pesar de estas claras ventajas, la propagación por tubérculos-semilla ha limitado, en cierta manera, la adopción y expansión del cultivo de la papa, especialmente en paises en desarrollo. Los tubérculos-semillas, que son caros y con frecuencia deben ser importados de paises productores de semilla, pueden representar más de la mitad del costo total de producción. Esto es especialmente cierto en los países de Africa del Norte y de Asia, donde se importa la mayor parte de los tubérculos-semillas.

Los tubérculos semilla son con frecuencia los principales portadores de plagas y enfermedades, las cuales pueden reducir los resultados considerablemente. Los tubérculos-semilla son perecibles, voluminosos y dificiles de transportar a áreas distantes de producción. Los tubérculos-semillas con frecuencia requieren ser almacenados en estructuras de almacenamiento refrigeradas que son costosas, pero a menudo necesarias para prevenir su pudrición en el almacén y para mantenerlos en condiciones fisiológicas adecuadas hasta la próxima temporada de siembra. Pero lo más importante es que los tubérculos que se usan para siembra, representan un volumen importante de alimento que está siendo enterrado en el campo, cuando podría, de otra manera, ser destinado al consumo. Las dos toneladas de tubérculo-semilla que se necesitan para sembrar una hectárea son suficientes para alimentar a una familia de cinco personas durante 8 años en el Sudeste de Asia, o a una familia similar de la serrania peruana durante 4 años. Debido a estos problemas, el Centro Internacional de la Papa junto con otras organizaciones e instituciones académicas y de investigacion como la Universidad Nacional de Tacna, está trabajando para desarrollar métodos alternativos en la producción de papa basados en la semilla botánica, que sean aplicables a las condiciones existentes en los paises del Tercer Mundo.

\section{MÉTODOS AVANZADOS DE MEJORAMIENTO EN SEMILLA BOTÁNICA}

El principal objetivo en un programa de mejoramiento de papa para su reproducción mediante semilla sexual es obtener progenies uniformes para caracteres agronómicos y reproductivos con resistencia a las principales enfermedades. Existen varias metodologias que pueden ser usadas para alcanzar esta meta: endocria, linea de parentales diploides que produzcan gametos $2 n$, y lineas parentales tetraploides (MENDOZA, 1980).

\subsection{ENDOCRIA}

Con la endocria puede alcanzarse el mayor nivel de uniformidad gamética. El resultado final sin embargo, sería completamente diferente al alcanzado en el maiz con este método de mejoramiento. Mendoza (1980) postuló que al cruzar dos genotipo, endocrinados y no emparentados, de papa autotetraploides, el hídrido tiene un coeficiente de endocria de $F=0.33$. Esto se debe a que el efecto de la endocria de los progenitores como en el caso del maiz, en el cual el coeficiente $F$, será cero. Por consiguiente, aunque la endocria da mayor nivel de uniformidad y homogeneidad gamética, y produce progenies completamente uniformes, también causa reducción fuerte en el rendimiento y disminuye la estabilidad del comportamiento.

Golmirzaie et al (1987) estudiaron el efecto de la endocria sobre el rendimiento y los caracteres agronómicos en diferentes generaciones de semilla sexual de papa. Las familias individuales expresaron depresión endogámica en diferentes grados, y la calidad de depresión varió entre los caracteres medidos. Los resultados mostraron que es posible seleccionar familias tetraploides para diferentes caracteres agronómicos y reproductivos que son menos deprimidos por efecto de la endocria.

\subsection{USO DE LINEAS PARENTALES DIPLOIDES $(2 n=2 x=24=A A)$.}

Peloquin et al (1983), han encontrado, en papas diploides, mutantes que presentan fallas durante el proceso meiotico produciendo gametos con el número cromosómico somático $2 \mathrm{n}$. Esto es el resultado de la restitución de la primera división (FDR), que transmitirá $80 \%$ del arreglo genético de los progenitores diploides en forma intacta a sus progenies tetraploides $(4 x \times 2 x=4 x)$. La importancia de los gametos $2 n$ para el mejoramiento reside no sólo en el logro de una heterozigosidad máxima en las progenies de apareamiento $4 x-2 x$, sino también en la producción de una adecuada homogeneidad en las progenies tetraploides. Macaso-Khwaja y Peloquin (1983), Mendoza (1980) y Ortiz e Iwanaga (1986) reportan que el uso de polen de FDR (2n) en cruzamientos $4 x-2 x$ es un mecanismo apropiado para tener uniformidad y vigor, dos características necesarias para la producción de semilla sexual de papa. En el uso de diploides existen, sin embargo, algunas 
limitaciones que necesitan ser consideradas: un periodo demasiado largo para alcanzar la maduración, caracteres agronómicos que necesitan ser mejorados y caracteres reproductivos que necesitan atención en el mejoramiento de clones diploides, antes de que estos puedan ser semilla sexual. El mejor uso de estos clones es transferir resistencia y a otros atributos especificos, encontrados a menudo sólo en especies diploides, a las especies tetraploides.

\subsection{USO DE LINEAS PARENTALES TETRAPOIDES $(2 n$ $=4 x=48=A A A A)$}

El uso de material parental tetraploide es el método más común para producir semilla sexual. Aunque el proceso meiótico produce gametos heterogéneos que resultaran en progenies heterogéneas, existen progenies tetraploides provenientes de cruzamientos $4 x-4 x$ con aceptable uniformidad $y$ alto rendimiento, especialmente si las lineas parentales tienen una amplia base genética (GOLMIRZAIE y MENDOZA, 1985), la investigación para la utilización de progenitores tetraploides llevada a cabo en el CIP incluye:

1) Los mejores cultivares del material disponible para el mejoramiento;

2) La evaluación de diferentes clones para la selección de líneas parentales;

3) EI desarrollo de diferentes tipos de cultivares, para el uso, por parte de los agricultores, como híbridos, lineas sintéticas, material para polinizacion libre. Además se está explorando la producción de híbridos (híbridos citoplasmáticos y heteroplastos) para la utilización de la esterilidad masculina.

\subsection{SELECCIÓNDE LINEAS PARENTALES DE SEMILLA SEXUAL}

Para eliminar los obstáculos en la expansión de los programas de producción de semilla sexual, los fitomejoradores deben seleccionar clones con buenos caracteres agronómicos y reproductivos. Una estrategia de mejoramiento basada en estas prioridades se concentraria, por consiguiente, en la selección de lineas parentales que produzcan flores y bayas bajo condiciones de clima cálido tropical.

En años recientes, el CIP empezó un proyecto en el Perú para evaluar y seleccionar líneas parentales con caracteres agronómicos y reproductivos adecuados a las condiciones de dias cortos y altas temperaturas de San Ramón ( 800 metros de altitud). Usando esta estrategia podemos seleccionar lineas parentales que florezcan bien y produzcan bayas bajo condiciones tropicales cálidas. Estas lineas parentales de semilla sexual pueden ser usadas fácilmente por el agricultor para obtener semilla de polinización libre, o por cualquier programa para producir hibridos o progenies sintéticas (estas progenies son obtenidas a partir de un número limitado de lineas parentales sembradas juntas en aislamiento en el campo para permitir su libre apareamiento).

\section{PRODUCCIÓN DE PAPA A BASE DE SEMILLA BOTÁNICA}

Con la semilla botánica, se pueden lograr cosechas de papa por: siembra en el campo, trasplante de plántulas al campo, y siembra de tubérculos-semillas producidos a partir de semilla botánica (seedling-tubers).

\subsection{SIEMBRA EN EL CAMPO}

La siembra de semilla botánica en el campo tiene posibilidades en aquellas áreas con temperaturas suaves, donde la lluvia es ligera y distribuida uniformemente durante las primeras cinco o seis semanas después de la siembra. Estas condiciones permiten buena germinación y el enraizamiento de las plántulas. Sin embargo, la siembra directa en el surco produce con frecuencia resultados inconsistentes.

Existen métodos que podrian facilitar la siembra en el campo, tales como el uso de semilla "peletizada», el uso de una suspensión de semilla en gel que se puede aplicar manual o mecánicamente, y el uso de una mezcla con musgo (mezcla iniciadora). Con este último método la semilla se pregermina en una mezcla de suelo y se siembra luego. En condiciones favorables, se puede lograr buena emergencia de plantas en la siembra directa de semilla botánica.

\subsection{TRASPLANTE AL CAMPO}

El trasplante de plántulas de semilla botánica al campo tiene varias ventajas sobre la siembra directa. Primero, las plantas permanecen menos tiempo en el campo, dejando ese campo libre para otros usos. La competencia con las malezas también se reduce, y las labores agrícolas se simplifican. Aun más, este método se adapta mejor a las prácticas acostumbradas en los sistemas agrícolas de países en desarrollo. 
La semilla botánica se puede sembrar en bandeja o almácigos. En climas cálidos el uso de sombra en los almácigos durante 15 a 20 dias después de la siembra, ayuda a lograr una emergencia más uniforme y un crecimiento vigoroso de las plántulas. La emergencia de las plántulas ocurre entre ocho y diez dias después de la siembra. Se ralea entre una semana y diez dias después de la emergencia. Aproximadamente 35 dias después de la siembra las plántulas están listas para ser trasplantadas.

Para reducir el estrés debido a condiciones adversas en el trasplante, las plántulas pueden ser trasplantadas con las raices cubiertas de tierra, usando para ello recipientes tales como cubos de compost, pequeñas bolsas hechas de hojas de plátano, o bandejas de diferentes materiales. Este sistema tendria mayor aplicación en zonas donde la práctica de trasplante es común en la producción de hortalizas cuando se siguen las prácticas adecuadas de manejo, las progenies adaptadas pueden producir más de 30 toneladas por hectárea.

\subsection{SIEMBRA DE TUBÉRCULOS - SEMILLAS PRODUCIDAS A BASE DE SEMILLA BOTÁNICA}

Los tubérculos obtenidos de plántulas producidas por semilla botánica pueden ser usados también muy ventajosamente para propagar el cultivo. Este método de producción combina las ventajas de la semilla botánica con las ventajas de sembrar tubérculos-semillas. Dependiendo de las condiciones ambientales, los tubérculos pueden ser producidos en almácigos con alta densidad de siembra o en surcos en el campo. Cuando se moja apropiadamente un almácigo puede producir, por metro cuadrado, hasta 800 tubérculos provenientes de plántulas. Los tubérculos provenientes de plántulas pueden ser usados para incrementar el suministro de tubérculo-semilla. Además, esos tubérculos pueden ser multiplicados para producir más papa para consumo. Buena performancia agronómica bajo condiciones de verano en Tacna ha sido observada en la familia tubérculo proveniente de semilla botánica (primera generacion clonal), del hibrido MFI x KATAHDYN.

\section{PRODUCCIÓN DE SEMILLA BOTÁNICA}

Cualquier programa sobre el uso de semilla botánica requiere que haya suministro en volúmenes y calidad adecuados. La semilla botánica puede ser producida siguiendo pasos similares a aquellos que se usan para la producción de semilla de otras hortalizas. Bajo condiciones apropiadas, las plantas de papa producen flores y luego producen frutos similares a tomates pequeños o sin madurar.

\subsection{POLINIZACIÓN}

La polinización puede ocurrir naturalmente o bajo condiciones controladas. Si las plantas se dejan en el campo para que den fruto naturalmente, la mayor producción de semilla resultante será de autopolinización debido a la naturaleza tetraploide de la papa (La autoincompatibilidad gametofitica sólo funciona en diploides). La producción de semilla de polinización cruzada que ocurra es causada principalmente por insectos. La semilla botánica asi obtenida es llamada "semilla de polinización libre" ya que solamente se conoce al material parental femenino. La semilla también puede ser producida por polinización manual controlada. En este caso, la semilla botánica es llamada "Progenie híbrida". Con la polinización controlada, el polen progenitor masculino es colocado en el estigma de la flor. Esto se puede hacer en campo o en el invernadero bajo condiciones controladas.

\subsection{COSECHA}

Unos cinco a diez dias después de la polinización, las bayas empiezan a desarrollarse. En cerca de 40 dias, estas bayas estarán listas para su cosecha. En condiciones de campo, una planta en floración producirá un promedio de 20 bayas. Cuando las bayas están maduras se cosechan y se guardan a temperatura ambiental hasta que estén lo suficientemente blandas para extraer suavemente la semilla. El número de semillas por baya puede variar desde 50 hasta 500 , aunque el promedio generalmente es de 200. Unas 1500 semillas pesan un gramo.

\subsection{ALMACENAMIENTO}

La semilla extraida de las bayas es secada a temperatura ambiental con humedad relativamente baja. La viabilidad de la semilla depende de la temperatura y del contenido de humedad de la semilla en su periodo de almacenamiento. Cuando se guarda a temperatura ambiental, la semilla botánica puede permanecer viable por varios meses hasta aproximadamente dos años. La semilla botánica puede ser almacenada por varios años a $4^{\circ}$ celsius sin perder su capacidad de germinación. Sin embargo, en ambos casos es esencial que la humedad relativa sea baja. La 
semilla botánica tiene un periodo de latencia más largo que el periodo de reposo de los tubérculos. Pero, a pesar de que dura de 4 a 9 meses, puede ser rota por un tratamiento simple con ácido giberélico

\section{PERSPECTIVAS DE LA SEMILLA BOTÁNICA}

La investigación sobre semilla botánica se está llevando a cabo en diversas zonas del mundo. Por ejemplo, la República Popular China es pionera en el uso a gran escala de la semilla botánica en un programa de multiplicación de papa, en el cual se reemplaza a la generación de tubérculos-semillas por semilla botánica. Un horticultor de Sri Lanka ha estado experimentando con semilla botánica desde 1962. En 1982 sembró casi cinco hectáreas de papas usando tubérculos producidos el año anterior a base de semilla botánica. $Y$ en algunos paises, ya venden comercialmente semilla botánica de papa, lo cual es otro indicio de su gran potencial (tab.5).

El Centro Internacional de la Papa (CIP), en el Perú complementa estos esfuerzos de investigación sobre semilla botánica, con estudios sobre los aspectos básicos de fisiologia, agronomia y genética de esa semilla. A través de cursos especiales de capacitación, el CIP facilita el intercambio de resultados entre científicos que están trabajando en semilla botánica en todo el mundo.

Aún se necesita más investigación para comprender el potencial total de la semilla botánica. Sin embargo, la tecnología de semilla botánica que se genera en el Centro Internacional de la Papa y en otros sitios puede ayudar a reducir los problemas de escasez y alto costo de tubérculos-semillas y a la vez ayudar a extender el cultivo de la papa a nuevas áreas de la zona tórrida donde es crítica la producción de alimentos.

\section{ADAPTACIÓN DE LA SEMILLA BOTÁNICA A ZONAS ÁRIDO-SALINAS}

A principios de 1986 se inicia, dentro del proyecto, investigaciones conducentes a la adaptación de lineas o familias de semilla botánica de papa a las zonas áridas y salinas del sur del Perú. Se evaluaron 63 familias hibridas con un total de 17000 genotipos (seedlings). Los estreses de calor y salinidad dañaron a las plantas trasplantadas en éstos suelos regados por gravedad o inundación parcial. No se seleccionó ninguna familia promisoria, sólo unos cuantos genotipos promisorios que sobrevivieron a las condiciones de estrés del desierto. Estos clones fueron multiplicados y sometidos a las pruebas serológicas de resistencia a virus. Los clones resistentes fueron adaptados a los estreses abióticos en Tacna. Algunos de ellos llegaron a la categoria de clon élite.

\subsection{EVILLUACIÓN DE HÍBRIDOS PROMISORIOS}

En 1991 se inicia otra estrategia y logística de evaluación de familias de TPS con progenies cuyos parentales habian sido previamente seleccionados por su tolerancia a estreses abióticos. EI experimento fue conducido en suelos áridos moderadamente salinos y utilizando riego por exudación. De 10 familias evaluadas se logró seleccionar la familia promisoria C89.437 x ST.BULK que mostró mayor frecuencia de genotipos adaptados con caracteres agronómicos deseables, seguido de la familia TPS $387776.3 \times$ ST.BULK.

A principios de 1994 se evaluó un set de nuevos hibridos TPS superiores en zonas áridas con suelos ligeramente salinos en diseños de blocks completamente randomizados con cuatro repeticiones. Las plántulas fueron cultivadas asociadamente con tubérculos-familias. Las familias TPS que más sobrevivieron a los estreses abióticos fueron SERRANA x LT.7 y LT.9 × TS.9. La variabilidad intra familias permitió seleccionar 24 clones promisorios con potencial genético para producción. Sin embargo las familias tubérculos, primera generación clonal de tuberculillos mostraron mayor adaptación a los estreses siendo los hibridos CHIQUITA $\times$ TS.4 y SERRANA $\times$ LT.7 los mejores rendidores en tubérculos lográndose seleccionar 30 genotipos promisorios. En términos de rendimiento ninguna de las familias de tubérculos o TPS superó al control COSTANERA. Las mismas 10 familias TPS evaluadas para rendimiento de tuberculillos en substratos artificiales (invernadero), mostraron variabilidad enorme en el rendimiento, siendo los híbridos SERRANA $\times$ LT.7 y LT. $9 \times 104.12$. LB los de mayor rendimiento de tuberculillos por $m^{2}(350-450$ tuberculillos $/ \mathrm{m}^{2}$ ). La familia TPS. SERRANA $\times$ LT.7 parece ser la mas adaptada a condiciones áridasy semisalinas; sin embargo, es necesario descartar experimentalmente alguna correlación positiva entre el efecto de estrés abiótico y la mayor producción de glycoalcaloides (solanina) en los tubérculos.

Durante el verano de 1995 se evaluaron diez familias de tuberculillos provenientes de semilla 
botánica cultivadas en sustratos de $1 \mathrm{~m}^{2}$. Los tuberculillos fueron sembrados en suelos áridos y ligeramente salinos. Las plantas mostraron un alto vigor ( 7 a 9 ) en el follaje, similar a los controles usados de semilla tubérculo de clones élites incluidas las variedades Tacna y Costanera (tab.4). Asi mismo todos las familias mostraron follaje normal, ausente de síntomas de enfermedades viróticas. La sobrevivencia de las plantas fue del $90 \%$ en contraposicion de las plántulas de semilla botánica anteriormente evaluadas (cerca del $40 \%$ de sobrevivencia). La mayor performancia agronómica en la producción de tubérculos fue observada en la familia SERRANA $\times$ LT.7 con una alta uniformidad de forma, tamaño y rendimiento (564 gr/planta). En segundo lugar se registra el híbrido LT.9 × 104.12 LB con un rendimiento de $528 \mathrm{gr} /$ planta pero la calidad de los tubérculos fue inferior. Ambos hibridos, provienen de parentales tolerantes al calor y resistentes a virus (tab.4).

Los resultados de este experimento muestra el potencial del uso de la semilla botánica y tuberculillos de primera generación clonal en el producción comercial de papa en zonas áridas y semisalinas.

\subsection{TAMIZADO DE TPS EN SUELOS ÁRIDOS $Y$ SALINOS}

Durante el otoño de 1995 se evaluaron 15 familias TPS cuyos progenitores fueron seleccionados en Tacna por su tolerancia a salinidad, sequia, calor, precosidad y resistencia a RKN. Se utilizó como control semilla de polinización libre de la variedad TIKAWASI. El experimento se llevó a cabo en Magollo 400 m.s.n.m. bajo condiciones de aridez y suelos agricolas fuertemente salinos a fin de conocer la habilidad combinatoria para salinidad y sequía a los clones elites parentales. Se utilizan 80 genotipos por familia distribuidos en BCR con cuatro repeticiones (20 plantas por repetición).

Las familias que mostraron mayor porcentaje de sobrevivencia a los 15 días de trasplante fueron SDC89.315 X ST.BULK, (72), SDC89.302 X SDC89.315 (71) y SDC90.259 x ST.BULK (65) el control TIKAWASI (14). La segunda evaluación de sobrevivencia realizada a 60 días después del trasplante muestra mayor frecuencia de plantas susceptibles. Los sobrevivientes mostraron un vigor de 1 a 3 , (no se registró mayor vigor) en las familias SDC91.934 x SDC89.315 (36); SDC90.259 x ST.BULK (30) y SDC89.308 X ST.BULK (27) (tab.3).

Sin embargo no hubo una fuerte correlación en algunas familias en la frecuencia de supervivencia y la producción de tubérculos de calidad habiendo tenido mayor producción las siguientes familias : SDC90.259 x ST.BULK, SDC91.934 x SDC89.315 x ST.BULK y SDC91.902 x SDC89.315 (tab.3).

El tamizado de estas 15 familias sugiere que los clones elites utilizados como parentales SDC89.315, SDC90.259 y SDC90.260 tienen una gran abilidad combinatoria para resistencia a suelos y salinos, debido a que proporcionan en la primera generación mayor frecuencia de hibridos o genotipos resistentes a salinidad consiguientemente las mejores combinaciones para suelos muy salinos serían : SDC90.259 $\times$ ST.BULK, SDC91.934 x SDC89.315 y SDC89.315 x ST.BULK.

\subsection{EVALUACIÓN DE HÍBRIDOS SUPERIORES}

En otoño de 1995 se utilizó una nueva e innovadora estrategia de producción de papa a partir de TPS en zonas árido salinas. Se seleccionaron previamente un grupo de diez hibridos superiores cuyos progenitores se asumia que tenian una gran abilidad combinatoria y cuyas semillas hibridas fueron seleccionadas por su alta calidad de embriones. El potencial genético de estos hibridos fueron puestos a prueba en suelos áridos y ligeramente salinos bajo condiciones de fotoperiodo corto, en Pachía, Tacna. El material fue trasplantado de almácigo al campo y el follaje fue cortado a los 80 dias a fin de determinar también su precosidad. Se evalúo la supervivencia y el vigor del follaje a los 60 días del trasplante. Los resultados obtenidos fueron sorprendentes:

a) Se observó una alta frecuencia de sobrevivencia de las plantas trasplantadas no antes registrada.

b) Se detectó un incremento conspicuo en el vigor general de las plántulas en las familias. En algunas familias y repeticiones se observó un grado de vigor 9 .

c) Se observó una mayor frecuencia de genotipos ideales para ser usados ya sea como clones promisorios o como futuros parentales para generar nuevas familias híbridas en zonas áridas, con un rendimiento de $900-1000 \mathrm{gr} /$ planta y excelente calidad de tubérculos y su extraordinaria precosidad. 
Las familias superiores que más destacan por su performancia general agronómica fueron: MF-I $X$ TS. 5 con $67.3 \%$ de supervivencia y vigor general promedio de 7.6 , MF-II $\times$ XY.13 con $83.5 \%$ de supervivencia y vigor general promedio de 7.5 , MFII $x$ TS. 13 con $46.4 \%$ de supervivencia y vigor general promedio de 7.4. En total de estos tres hibridos superiores se seleccionaron 57 genotipos por la arquitectura ideal de la planta (tab. 1,2).

Estos mismos hibridos superiores han sido evaluados normalmente en las mismas condiciones edáficas pero bajo condiciones de dias largos, es decir en invierno-primavera (julio, agosto y setiembre) (tab.1). Los mejores híbridos de buena performancia agronómica fueron los cruces MF.I X KATAHDYN y TPS.67 SELF. Las mejores familias seleccionadas bajo dias cortos mostraron baja performancia agronómica bajo condiciones de fotoperíodo largo ( tabla 1, 2 ).

\section{REFERENCIAS BIBLIOGRÁFICAS}

accatino, P. MAlagamba, P. 1982. Potato Production from True Seed. International Potato Center. Lima-Peru.

AMAERUS,M. 1987. True Potato Seed. p. 11-14. In Abstracts of EAPR. (Véase Golmirzaie et al).

ATLIN. G. 1984. Farmer Maintenance of TPS varieties. In: Report of Planning Conference of Innovative Methods for Propagating Potatoes. CIP. Lima-Peru.

CHAVEZ, R. 1990. Cultivo de Raíces y Tubérculos, FCAG-UNJBG. Tacna-Peru.

CHAVEZ, R. 1991. Cultivo in Vitro en el Mejoramiento Genético de Plantas. Nueva Imagen. UNJBG, Tacna-Peru.

CHAVEZ, R. MENDOZA, H. ESPINOZA, J. AREVALO, N. DIAZ, L. 1992. Estrategias y Ganancia Genética en el Mejoramiento de Papa y Camote para Zonas ÁridoSalinas. Nueva Imagen, Tacna-Peru.

CHAVEZ, R. MENDOZA, H. ESPINOZA, J. SILES, P. HUACOLLO, M. FLORES, J. 1993. Ampliando la base genetica en el germoplasma mejorado de papa y camote. Revista de investigacion Nueva Imagen 1993.

CHAVEZ, R. 1995. Clones superiores de papa y camote adaptados a zonas arido-salinas. Rev. Inv. Ciencia \& Desarrollo 1995.

GERRES, A.M.W. 1988. Introduction of potato to remove mountain areas of China through TPS in 1906. p. 167-169. In Asian Potato Association Proceedings. Second Triennial Conference, Kunming, China, June 1226. Manila: Asian Potato Association, $250 \mathrm{p}$.

GOLMIRZAIE, A. MENDOZA, H. 1986. Effect of Early Selection for Seedling Vigor on Open-pollinated True Potato Seed. Amer. Potato 5.63:426 (abst.)

GOLMIRZAIE, A. ORTIZ, R. SERQUEN, F. 1990. Genética y

\subsection{PROSPECCIÓN FUTURA DE TPS ENZONAS ÁRIDO SALINAS}

Los resultados promisorios de estos experimentos muestran la factibilidad de la producción de semilla de papa a partir de TPS libre de enfermedades viróticas en zonas áridas y suelos poco salinos. Sin embargo es necesario ampliar la base genética de la TPS para tolerancia a estreses abióticos en zonas áridas. En este sentido se ha programado la utilización de familias TPS cuyos parentales, en lo posible masculino y femenino sean muy precoces y tolerantes al calor, salinidad y sequia y tengan buena habilidad combinatoria general para el vigor de las plántulas antes de ser transplantadas al campo de cultivo. En la actualidad se esta evaluando un grupo de 67 nuevas familias avanzadas de TPS bajo condiciones de verano, es decir de fotoperiodo largo.

Mejoramiento de la Papa mediante semilla (sexual). CIP, Lima-Peru

GOLMIRZAIE, A.M. 1985a. Earliness in TPS progenies. True Potato Seed (TPS) Letter 6(2):1.

GOLMIRZAIE, A.M. 1985b. CIP Progress Report, Vol.1, Lima-Peru.

GOLMIRZAIE, A.M. 1987. Performance of TPS synthetic population. Am. Potato J. 64:440 (Compendio).

GOLMIRZAIE, A.M. 1988, Comparison of different open-pollinated generation for agronomical characters. p. 77-79. In Asian Potato Assn. Proc.

GOLMIRZAIE, A.M.; BRETSCHNEIDER, K; ORTIZ, R. 1987. In breeding effect on the production and agronomical characters of different true potato seed generations. p. 294-295. In Abstracts of Tenth Triennial Conference of the European Association for Potato Research, Aalboro, Denmark, July 26-31.

GOLMIRZAIE, A.M.; MENDOZA, H.A. 1985. Identification of parental lines for development of true potato seed (TPS) population. Am. Potato. J. 62:427-428. (Compendio).

GOLMIRZAIE, A.M.; MENDOZA, H.A. 1986. Effect of early selection for seedling vigor on open-pollinated true potato seed. Am. Potato J. 63:426. (Compendio).

HORTON, D. 1992. La Papa: Producción, Comercialización y Programas. Copublicacion del CIP, Lima-Peru. Editorial Hemisferio Sur, Montevideo.

INTERNATIONAL POTATO CENTER. 1987. Annual Report CIP 1986-1987. Lima-Peru. p.27.

MACASO-KHWAJA, A.C.; PELOQUIN, S.J. 1983. Tuber yield of families from op and hybrids tps. Am. potato J. 60 : 645-652. 
MALAGAMBA, P. 1984. Agronomic Management for Transplanting TPS Seedling. In: Report of Planning Conference of Innovative Methods for Propagating Potatoes. CIP, Lima-Peru.

MALAGAMBA, P. 1988. Potato production from true seed in tropical climates. HortScience 23:495-500.

MALAGAMBA, P.; MONARES, A. 1988. True Potato seed: past and present uses. Lima : International Potato Center. $7 p$.

MALISA, P. 1980. The need and The search for genetic markers in plant cell cultures, p. 107-114. In F. Salov et al. (eds), Plant cell cultures: results and perspectives, Amsterdam: Elsevier/North Holland Biomedical Press.

MENDOZA, H. 1979. Preliminary Results of Yield and Uniformity of Potatoes Grown from True Seed. In: Report of Planning Conference on the Production of Potato from True Seed. CIP, Lima-Peru.

MENDOZA, H. 1983. Selection of Uniform Progenies to use TPS in Commercial Potato Production. In: Report of Planning Conference on Present and Future Strategies for Potato Breeding and Improvement. CIP, Lima-Peru.

MENDOZA, H.A. 1980. Preliminary results on yield and uniformity of potatoes grown from true seed, p. 156-172. In Report of planning conference on the production of potatoes from true seed, september 13-15, 1979. Manila, Philippines. Lima: International Potato Center. 172p.
MENDOZA, H.A. 1983. Breedding of potato population at the Internacional Potato Center CIP Circular 11:1-5.

ORTIZ. R.; IWANAGA, M. 1986. Manipulacion de niveles de ploidia en papa. Evaluación agronomica de progenies tetrapolides derivadas de cruzamientos $4 x-2 x$. Primer congreso Peruano de Genética, Lima-Peru. 813 diciembre, p.15.

PELOQUIN, S.J. 1983. New approaches to breeding for the potato of the year 2000.p. 32-34. In W.J. Hooker (ed.) 2000. Proceedings International Congress, Lima-Peru. February 22-27. 1982. Lima: International Potato Center. $199 p$.

SONG BO-FU; QU DONG YU; VANDER ZAAG, P. 1987 True Potato seed in China: past, present, and future. Amer. Potato J. 64:321-328.

THOMPSON, P.G.; MENDOZA, H.A.; PLAISTED, R.L. 1983 Estimation of genetic parameters for characters related to potato propagation of true seed (TPS) in an andigene population. Am. Potato. J, 60:393-401.

WIERSEMA, S. 1988. Evaluación de Tecnología para la producción de Tubérculos Semilla de Semilla Botánica de Papa. Serie de Evaluación de Tecnología No. 8. CIP, Lima-Peru.

WIERSEMA, S. 1988. Produccion de Tuberculos Semilla Derivados de la Semilla Botanica. Circular Volumen 13. CIP, Lima-Peru.

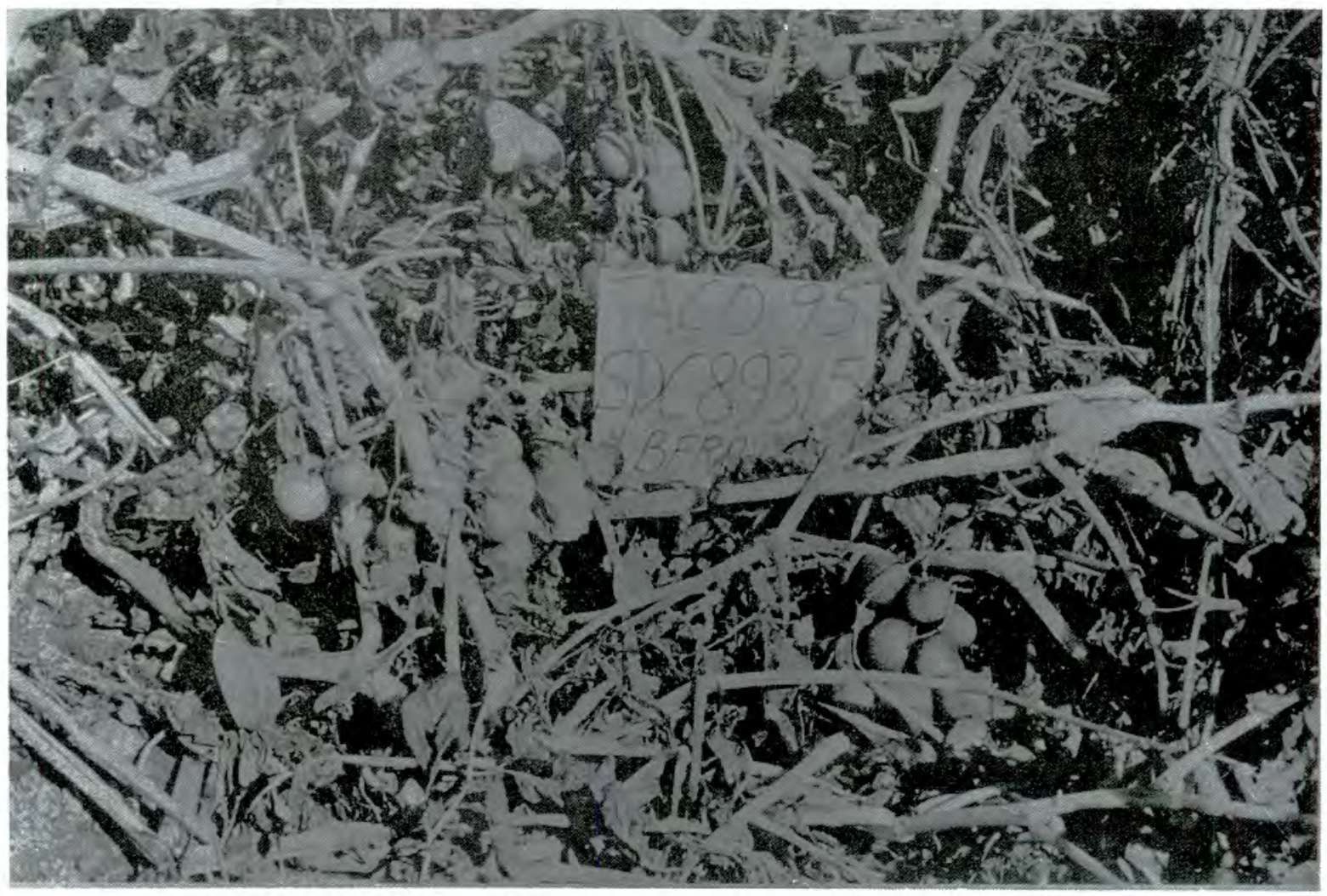

El clon élite SDC89.315 resistente a estreses abióticos posee una buena habilidad combinatoria para caracteres agronómicos y resistencia a estreses abióticos en zonas árido-salinas. Además tiene una alta fertilidad y producción de bayas y semillas viables que la capacitan para ser progénitos superiores de TPS. 
TABLA N 01: Evaluación de familias superiores TPS bajo condiciones de invierno en tierras áridas con bajos niveles de salinidad. Localidad: Pachia Alta, Tacna, 100 m.s.n.m. Invierno 1995. Período de crecimiento: 80 dias, en condiciones de dias. cortos a dias largos.

\begin{tabular}{|c|c|c|c|c|c|c|c|}
\hline$\underset{N^{\circ}}{\text { FAMILIA }}$ & HIBRIDOS CRUZADOS & $\begin{array}{l}\text { NoDE } \\
\text { PLANTAS } \\
\text { TRASPL. }\end{array}$ & $\begin{array}{c}\text { NDDE } \\
\text { PLANTAS } \\
\text { SOBREV. } \\
45 \mathrm{D} .\end{array}$ & $\begin{array}{l}\text { NoDE } \\
\text { PLANTAS } \\
\text { SOBREV. } \\
60 \mathrm{D} .\end{array}$ & $\begin{array}{c}\text { VIGOR } \\
\text { GENERAL } \\
1-9 \\
x\end{array}$ & $\begin{array}{l}\text { No DE } \\
\text { GENOT. } \\
\text { SELECT } \\
\text { ARCHI.F }\end{array}$ & $\begin{array}{l}\text { No } \\
\text { CLONES } \\
\text { PROMET } \\
\text { SELECC. }\end{array}$ \\
\hline 1 & MF I. KATAHDIN & 231 & 198 & 164 & 4.6 & 0 & 1 \\
\hline 2 & TPS.67.SELF & 109 & 95 & 86 & 4.3 & 13 & 0 \\
\hline 3 & MF $1 \times T S .3$ & 68 & 49 & 40 & 4 & 0 & 1 \\
\hline 4 & MF.II $\times$ TS. 13 & 5 & 5 & 4 & 3 & 0 & 0 \\
\hline 5 & $M F .1 \times X Y .13$ & 160 & 78 & 60 & 4 & 3 & 3 \\
\hline 6 & MF $\| 1 \times$ TS 9 & 39 & 9 & 7 & 3 & 0 & 0 \\
\hline 7 & MF.I $\times$ TS. 9 & 73 & 24 & 18 & 3 & 0 & 0 \\
\hline 8 & CHIQUITA $\times$ CEW69.1 & 44 & 33 & 28 & 3 & 3 & 0 \\
\hline 9 & CEW69.1 ×104.12.LB & 35 & 23 & 20 & 3 & 1 & 0 \\
\hline 10 & MF $\| \times$ TS 13 & 134 & 84 & 72 & 4 & 2 & 0 \\
\hline 11 & MF. I $\times$ TS. 5 & 237 & 75 & 60 & 5.8 & 4 & 3 \\
\hline
\end{tabular}

TABLA N ${ }^{\circ}$ 02: Evaluación de familias hibridas superiores TPS bajo condiciones de invierno en tierras áridas con bajos niveles de salinidad. Localidad: Pachia, Tacna, 1000 m.s.n.m. Otoñoinvierno 1995. Follaje cortado a los 80 días. Período de crecimiento: 80 dias, en condiciones de crecimiento de dias largos a dias cortos.

\begin{tabular}{|c|c|c|c|c|c|c|c|c|}
\hline$N^{p}$ & FAMILIA TPS & $\begin{array}{l}\text { TIPO DE } \\
\text { EMBRION }\end{array}$ & $\begin{array}{c}N^{N} D E \\
\text { PISemb. }\end{array}$ & $\begin{array}{c}\text { NODE } \\
\text { PLANTAS } \\
\text { SOBREV. }\end{array}$ & SOBREV & $\begin{array}{l}\text { VIGOR } \\
\text { GENERAL } \\
\text { GO D. }\end{array}$ & $\begin{array}{c}\text { NoDE } \\
\text { GENOT } \\
\text { SELECC. }\end{array}$ & $\begin{array}{l}\text { NeOF } \\
\text { PAR. } \\
\text { CLONES }\end{array}$ \\
\hline 1 & MF-1 x TS .5 & $A A$ & 222 & 187 & 67.3 & 7.6 & 25 & 5 \\
\hline 2 & $M F=1 \times X Y .13$ & AA & 249 & 232 & 83.5 & 7.5 & 15 & 6 \\
\hline 3 & MF- $\| x$ TS 13 & AA & 173 & 129 & 46.4 & 7.4 & 17 & 4 \\
\hline 4 & TPS-67 SELF & $A A$ & 132 & 114 & 41.0 & 7.0 & 3 & 6 \\
\hline 5 & CEME9.1×104 12LB & $A A \times B B$ & 37 & 32 & 11.5 & 7.0 & 3 & 3 \\
\hline 6 & MF- $\| x$ TS .9 & A & 89 & 50 & 18.0 & 5.6 & 3 & 0 \\
\hline 7 & MF- $11 \times$ TS .9 & A & 37 & 30 & 10.8 & 5.0 & 1 & 0 \\
\hline 8 & MF $-1 \times \mathrm{TS} .3$ & AB & 34 & 28 & 10.1 & 5.0 & 2 & 0 \\
\hline 9 & CMIOUTRAXCEW $=1$ & A & 71 & 49 & 17.6 & 4.5 & 3 & 4 \\
\hline 10 & MF-I X KATAHDIN & AA & 278 & 171 & 61.5 & 4.2 & 8 & 8 \\
\hline
\end{tabular}

- $N^{0}$ de genotipos seleccionados por la arquitectura ideal de la planta

* Clones individuales seleccionados por su rendimiento y calidad de tubérculo

TABLA N ${ }^{\circ}$ 03: Evaluación de familias hibridas TPS, bajo condiciones de suelo árido y salino. Las familias TPS fueron generadas de clones resistentes a salinidad y sequia en Tacna. Localidad: Magollo, Tacna, 400 m.s.n.m. Invierno 1995, CE: 08.2 - 13.52 mh. Disefio: BCR, cuatro repeticiones 20 plantas/repetición.

\begin{tabular}{|c|c|c|c|c|c|}
\hline \multirow{2}{*}{$\begin{array}{c}N^{\circ} \\
\text { ORDEN }\end{array}$} & \multirow{2}{*}{ FAMILIA TPS } & \multicolumn{2}{|c|}{ TOTAL } & \multicolumn{2}{|c|}{ FRECUENCIA } \\
\hline & & NoPS & $\stackrel{N P C}{*}$ & \%PS & $\% P C$ \\
\hline 1 & SDC91.934 × SDC89.315 & 36 & 26 & 45.0 & 32,5 \\
\hline 2 & SDC90.259 × ST.BULK & 30 & 27 & 37.5 & 33.8 \\
\hline 3 & SDC89.308 $\times$ ST. BULK & 27 & 14 & 33.8 & 17.5 \\
\hline 4 & SDC89.315 x ST.BULK & 26 & 22 & 32.5 & 27.5 \\
\hline 5 & SDC91.628 x SDC90.266 & 25 & 13 & 31.3 & 16.3 \\
\hline 6 & SDC89.302 $\times$ SDC89. 315 & 24 & 17 & 30.0 & 21.3 \\
\hline 7 & SDC91.019 x SDC91.640 & 24 & 10 & 30.0 & 12.5 \\
\hline 8 & SDC 90.266 x ST.BULK & 24 & 4 & 30.0 & 5.0 \\
\hline 9 & SDC $91.027 \times$ SDC89.315 & 24 & 9 & 30.0 & 11.3 \\
\hline 10 & $387776.3 \times$ ST BULK & 23 & 12 & 28.8 & 15.0 \\
\hline 11 & SDC91.902 × SDC89 315 & 23 & 21 & 28.8 & 26.3 \\
\hline 12 & SDC $90.260 \times$ ST. BULK & 22 & 18 & 27.5 & 22.5 \\
\hline 13 & SDC $91.750 \times$ SCD90.286 & 20 & 11 & 25.0 & 13.8 \\
\hline 14 & COSTANERA $\times 104.12 . \mathrm{LB}$ & 19 & 7 & 23.8 & 8.8 \\
\hline 15 & SDC92.014 x SDC91.840 & 13 & 5 & 16.3 & 6.3 \\
\hline \multirow{3}{*}{$\begin{array}{r}16 \\
p 19.1 \ldots \\
\end{array}$} & TIKAWASI-OP (CONTROL) & 2 & 0 & 2.5 & 0.0 \\
\hline & TOTAL & 362 & 216 & 452.5 & 270 \\
\hline & PROMEDIO & & & 28.3 & 16.9 \\
\hline
\end{tabular}

- $\mathrm{N}^{0}$ Plantas sobrevivientes a los 60 dias de transplante.

- No Plantas tubérculo cosechadas, algunos genotipos han mostrado resistencia de campo a la mosca minadora y estan siendo evaluadas en Lima.
TABLA N ${ }^{\circ}$ 04: Performancia agronómica de familias de tubérculos de hibridos TPS comparados con clones elites resistentes a estreses bajo condiciones de suelos aridos y baja salinidad. Localidad: pachía, 1000 m.s.n.m. 1995. Primavera-verano. Periodo de crecimiento: 90 dias: evaluación a los 90 días.

\begin{tabular}{|c|c|c|c|c|}
\hline $\begin{array}{l}\text { CLON ELITE* } \\
\text { Y FAMILIA TPS }\end{array}$ & $\begin{array}{c}\text { VIGOR } \\
\text { FOLLA.JE } \\
1.9\end{array}$ & $\underset{\%}{\text { COBERTURA }}$ & $\begin{array}{c}\text { DEGRADACION } \\
\text { DE } \\
\text { SENESC. }\end{array}$ & $\begin{array}{l}\text { PERFORMANCIA } \\
\text { AGRONOMICA** } \\
\text { (TUBERCULOS) }\end{array}$ \\
\hline 1. SDC 9.132 & 7 & 70 & 7 & 5 \\
\hline 1. LT.9- 104,12 LB & 9 & 90 & 5 & 5 \\
\hline 2. DESIREE (Check) & 7 & 70 & 7 & 3 \\
\hline 2. SERRANA $\times$ LT -7 & 9 & 90 & 5 & 7 \\
\hline 3. SDC92.172 & 7 & 70 & 7 & 5 \\
\hline 3. CHIQUITA $\times$ TS -4 & 9 & 100 & 5 & 5 \\
\hline 4. SDC91.640 & 9 & 90 & 7 & 9 \\
\hline 4. LT.9 $\times$ TS. 10 & 9 & 90 & 5 & 3 \\
\hline 5. SDC 91.750 & 7 & 80 & 5 & 5 \\
\hline 5. LT $-9 \times$ TS 3 & 9 & 100 & 5 & 5 \\
\hline 6. MARIVA (Check) & 5 & 40 & 3 & 1 \\
\hline 6. MF-\|x TS.9 & 9 & 100 & 5 & 3 \\
\hline 7. SDC89.315 & 9 & 100 & 7 & 7 \\
\hline 7. LT. $8 \times$ LT.7 & 9 & 85 & 7 & 3 \\
\hline 8. SDC89.308 & 7 & 60 & 5 & 3 \\
\hline 8. TS $-9 \times$ TS -5 & 9 & 95 & 5 & 5 \\
\hline 9. SDC89.262 & 7 & 80 & 5 & 5 \\
\hline 9. SERRANA x TPS -113 & 7 & 90 & 3 & 5 \\
\hline 10. REVOLUTION (Check) & 5 & 50 & 7 & 3 \\
\hline 10. CHIQUITA $\times$ TS 9 & 5 & 50 & 7 & 3 \\
\hline 11. SDC91.612 & 9 & 90 & 7 & 7 \\
\hline
\end{tabular}

- Performancia agronómica basada en la calidad de producción comercial del tubéculo.

- Es stock de plantas de clones élites y variedades usadas son de tercera generación clonal de Tacna.

TABLA N ${ }^{\circ}$ 05: Descripción de dos hibridos superiores de semilla botánica liberados por el CIP para su distribución internacional.

\begin{tabular}{|c|c|}
\hline HPS-7/67 & MAINE-28x104.12LB \\
\hline PLANTA: & PLANTA: \\
\hline $\begin{array}{l}\text { Tallos fuertes de color verde claro, de } 90 \\
\text { a } 100 \mathrm{~cm} \text {. Hojas grandes, con foliolos } \\
\text { medianos de color verde claro. Flores } \\
\text { blancas. }\end{array}$ & $\begin{array}{l}\text { Tallos fuertes de color verde oscuro con } \\
\text { pigmentación en su base de } 90 \text { a } 100 \mathrm{~cm} \text {. } \\
\text { Hojas medianas, con foliolos color verde } \\
\text { oscuro. Flores amarillas y lilas. }\end{array}$ \\
\hline TUBERCULOS: & TUBERCULOS: \\
\hline $\begin{array}{l}\text { Redondos-oblongos yachatadosconojos } \\
\text { semiprofundos. Cascara crema y pulpa } \\
\text { blanca. Brotes verde oscuro sin } \\
\text { pigmentación. }\end{array}$ & $\begin{array}{l}\text { Redondo achatado con ojos } \\
\text { semiprofundos y pigmentados. Cascara } \\
\text { crema y pulpa blanca. }\end{array}$ \\
\hline PERIODO VEGETATIVO: & PERIODO VEGETATIVO; \\
\hline Semiárido ( 110 a 120 dias) & Semiprecoz (90 a 100 dias). \\
\hline RENDIMIENTO: & RENDIMIENTO: \\
\hline $\begin{array}{l}\text { Alto ( } 35 \text { a } 40 \mathrm{~T} / \mathrm{Ha} \text { ), } 85 \% \text { de tubérculos de } \\
\text { tamaño comercial. }\end{array}$ & $\begin{array}{l}\text { Alto ( } 35 \text { a } 40 \mathrm{~T} / \mathrm{Ha} \text { ), } 90 \% \text { de tubérculos de } \\
\text { tamaño comercial. }\end{array}$ \\
\hline ADAPTACION: & ADAPTACION: \\
\hline $\begin{array}{l}\text { Rústica, se adapta a climas templados y } \\
\text { cálidos. }\end{array}$ & $\begin{array}{l}\text { Rústica, se adapta a climas templados y } \\
\text { frescos. }\end{array}$ \\
\hline CALIDAD DE TUBERCULOS: & CALIDAD DE TUBERCULOS: \\
\hline Buena, contenido de materia seca $21.7 \%$ & Buena, contenido de materia seca $18.6 \%$ \\
\hline RESISTENCIA A ENFERMEDADES & RESISTENCIA A ENFERMEDADES: \\
\hline Tolerante a virus y a tizón tardio. & Tolerante a virus y a tizón tardio. \\
\hline
\end{tabular}

